\title{
The role of dopaminergic transmission through D1-like and D2-like receptors in amphetamine-induced rat ultrasonic vocalizations
}

\author{
Jennifer M. Wright • May R. S. Dobosiewicz • \\ Paul B. S. Clarke
}

Received: 20 July 2012 / Accepted: 2 September 2012 / Published online: 28 September 2012

(C) Springer-Verlag 2012

\begin{abstract}
Rationale Systemic amphetamine (AMPH) administration increases the rate of $50-\mathrm{kHz}$ ultrasonic vocalizations (USVs) in adult rats and preferentially enhances the 'trill' subtype; these effects of AMPH critically depend on noradrenergic transmission, but the possible contributions of dopamine are unclear.

Objective To assess the role of dopamine in $50-\mathrm{kHz}$ USVs emitted drug-free and following systemic AMPH administration.

Methods Adult male Long-Evans rats pre-selected for high AMPH-induced calling rates were tested with AMPH $(1 \mathrm{mg} / \mathrm{kg}$, intraperitoneal (IP)) and saline following pretreatment with the following dopamine receptor antagonists: SCH $23390(0.005-0.02 \mathrm{mg} / \mathrm{kg}$, subcutaneous (SC)), SCH 39166 (0.03-0.3 mg/kg, SC), haloperidol (0.1, $0.2 \mathrm{mg} / \mathrm{kg}$, IP), sulpiride (20-80 mg/kg, SC), raclopride (0.1-0.5 mg/kg, SC), clozapine (4 mg/kg, SC), risperidone $(0.5 \mathrm{mg} / \mathrm{kg}, \mathrm{SC})$, and pimozide $(1 \mathrm{mg} / \mathrm{kg}$, IP). The dopamine and noradrenaline reuptake inhibitors (GBR 12909 and nisoxetine, respectively) were also tested, alone and in combination.

Results SCH 23390, SCH 39166, haloperidol, and raclopride dose-dependently inhibited vocalizations under AMPH and suppressed the proportion of trill calls. Sulpiride,
\end{abstract}

Electronic supplementary material The online version of this article (doi:10.1007/s00213-012-2871-1) contains supplementary material, which is available to authorized users.

J. M. Wright • M. R. S. Dobosiewicz • P. B. S. Clarke $(\triangle)$

Department of Pharmacology and Therapeutics,

McGill University,

McIntyre Medical Building Rm. 13203655 Promenade Sir

William Osler,

Montreal, QC H3G 1Y6, Canada

e-mail: paul.clarke@mcgill.ca however, had no discernable effect on call rate or profile, even at a high dose that reduced locomotor activity. Single doses of clozapine, risperidone, and pimozide all markedly decreased calling under saline and AMPH. Finally, GBR 12909 and nisoxetine failed to promote 50-kHz USVs detectably or alter the subtype profile, when tested alone or in combination.

Conclusions The rate of 50-kHz USVs and the call subtype profile following systemic AMPH administration depends on dopaminergic neurotransmission through D1-like and D2-like receptors. However, inhibiting dopamine and/or noradrenaline reuptake appears insufficient to induce calling.

Keywords Ultrasonic vocalization · Amphetamine · Dopamine $\cdot$ Noradrenaline $\cdot$ Atypical antipsychotic . Dose-response $\cdot$ D1 receptor $\cdot$ D2 receptor $\cdot$ Hedonia $\cdot$ Affect

\section{Introduction}

Higher-frequency ultrasonic vocalizations (USVs) emitted by adult laboratory rats, generally termed " $50-\mathrm{kHz}$ calls" (for review, see Brudzynski 2009; Wohr and Schwarting 2010), are frequently associated with appetitive stimuli (Burgdorf et al. 2010; Knutson et al. 2002) and have been proposed to reflect positive affect (Brudzynski 2007; Burgdorf and Moskal 2009; Burgdorf et al. 2010). However, $50-\mathrm{kHz}$ USVs are acoustically diverse, with many identified subtypes including flat (i.e., constant frequency) calls and at least 12 types of frequency-modulated (FM) calls (Wright et al. 2010). The relative prevalence of the different call subtypes, which we have termed the "call profile" (Wright et al. 2010), can be experimentally modified independently of the 
overall rate of 50-kHz call emission (Ciucci et al. 2007, 2009; Wright et al. 2012b).

Dopaminergic (DAergic) neurotransmission appears to play a key role in USV emission. Notably, acute systemic injection of the dopamine (DA) agonist apomorphine promoted 50-kHz calls (Williams and Undieh 2010), and intraaccumbens administration of the $\mathrm{D}_{2} / \mathrm{D}_{3}$ agonist quinpirole modulated USV production in a dose-related triphasic fashion (Brudzynski et al. 2012). Conversely, DA receptor antagonists are reported to inhibit $50-\mathrm{kHz}$ USVs elicited by several natural and artificial rewarding stimuli, namely systemic cocaine (Williams and Undieh 2010), intracerebral amphetamine (AMPH) and glutamate (Thompson et al. 2006; Wintink and Brudzynski 2001), tickling (Burgdorf et al. 2007), electrical brain stimulation (Burgdorf et al. 2007), and copulation-related contexts (Bialy et al. 2010; Ciucci et al. 2007, 2009).

The psychostimulant AMPH, which enhances both DAergic and noradrenergic transmission (McKittrick and Abercrombie 2007), exerts two principal effects on $50-\mathrm{kHz}$ vocalizations: It increases the overall call rate (Ahrens et al. 2009; Simola et al. 2009; Wintink and Brudzynski 2001; Wright et al. 2010, 2012b), and in relative terms, it shifts the "call profile," thereby enhancing the trill subtype while suppressing flat calls (Wright et al. 2010, 2012b). These rate-enhancing and call profile-altering effects of AMPH are critically dependent on $\alpha_{1}$ and $\beta$ adrenergic receptor function, respectively (Wright et al. 2012b). To our knowledge, however, it has not been determined whether the effects of systemic AMPH administration on $50-\mathrm{kHz}$ USV emission are also dependent on DAergic transmission.

The first main aim of the present study was therefore to test the hypothesis that DAergic neurotransmission is required for $50-\mathrm{kHz}$ calls that are emitted when tested drugfree or following systemic AMPH administration. The second, related, aim was to determine whether either D1-like or D2-like DA receptors (Le Foll et al. 2009) play a role. These questions were addressed in Experiments 1-7, in which we tested the effects of acute pretreatment with several D1- or D2-like DA receptor antagonists in combination with systemic saline or AMPH challenge (see Table 1). During testing, it emerged that the atypical antipsychotic drug sulpiride (Rama Rao et al. 1981) did not inhibit AMPHinduced calling, in striking contrast to two classical D2 antagonists (i.e., haloperidol and raclopride). Therefore, as a third aim, we assessed whether sulpiride's lack of effect reflected its atypical antipsychotic profile, by testing two other atypical neuroleptic drugs (clozapine and risperidone) and one additional classical D2 antagonist (pimozide). We also recorded USVs and locomotor activity simultaneously (Experiment 7), in order to confirm that sulpiride was behaviorally active, despite its failure to influence $50-\mathrm{kHz}$ calling.
A final aim was to address whether enhancing DA or noradrenaline (NA) transmission is sufficient to induce 50$\mathrm{kHz}$ USVs or affect the call profile (Experiments 8-10 - see Table 1). To this end, rats were acutely challenged with the selective DAT inhibitor GBR 12909 and the selective NET inhibitor nisoxetine, given alone and in combination.

\section{Methods}

\section{Subjects}

Subjects were 114 male Long-Evans rats (Charles River Laboratories, St Constant, Quebec, Canada), weighing 376 $\pm 50 \mathrm{~g}($ mean $\pm \mathrm{SD})$ at the start of the experiment. They were housed two or three per cage $\left(25 \times 48 \times 20 \mathrm{~cm}^{3}\right)$ in a temperature- and humidity-controlled colony room (19$20{ }^{\circ} \mathrm{C}, 50-60 \%$ ) at the McGill University Animal Research Center. Rats were maintained on a reverse 12:12 light/dark cycle, with lights off at $0700 \mathrm{~h}$. All behavioral testing took place during the dark phase of the cycle. Food and water were available ad libitum, except during testing sessions. In all experiments, rats were initially drug- and experimentally naïve, with the following exceptions: In Experiments 3 and 4 , rats had received four prior systemic injections of AMPH $(0.25,0.5,1$, and $2 \mathrm{mg} / \mathrm{kg}$, IP), and in Experiment 7, rats had received four prior administrations of morphine $(1 \mathrm{mg} / \mathrm{kg}$, SC). All procedures were approved by the McGill Animal Care Committee in accordance with the guidelines of the Canadian Council on Animal Care.

\section{Overview of experiments}

Ten experiments were performed, as summarized in Table 1. Briefly, Experiments 1-7 tested the effects of antagonist pretreatment on the USV response (i.e., call rate and subtype profile) to systemic AMPH. Experiment 7 additionally examined locomotor activity during the USV recording. The acute USV responses to the DA and NA reuptake inhibitors (i.e., GBR 12909 and nisoxetine), given alone or in combination, were examined in Experiments 8-10.

\section{Experimental protocol}

AMPH screen A significant minority of rats emit few calls in response to systemic AMPH (Wright et al. 2010). Therefore, subjects in most experiments were initially screened for AMPH-induced calling. Exceptionally, in order to reduce pre-experiment drug exposure, subjects in Experiments 3,4 , and 7 were not screened since they had already received prior AMPH or morphine administration (see above). The AMPH screening method was as described previously (see Wright et al. 2012b for further details). Briefly, rats 
Table 1 Summary of experiments

\begin{tabular}{llllll}
\hline Experiment & Pretreatment & Doses, $\mathrm{mg} / \mathrm{kg}$ & Route & Time before saline/AMPH, min & $n$ \\
1 & SCH23390 & $0.005,0.01,0.02$ & SC & 20 & 10 \\
2 & SCH39166 & $0.03,0.1,0.3$ & SC & 30 & 12 \\
3 & Haloperidol & $0.1,0.2$ & IP & 60 & 12 \\
4 & Sulpiride & 20,40 & SC & 60 & 12 \\
5 & Raclopride & $0.1,0.2,0.5$ & SC & 30 & 12 \\
& Sulpiride & 40,80 & SC & 30 & 12 \\
6 & Clozapine & 4 & SC & 30 & \\
& Risperidone & 0.5 & SC & 30 & 16 \\
7 & Pimozide & 1 & IP & 30 & \\
Experiment & Sulpiride & 80 & SC & 30 & 8 \\
8 & Drug & Doses, $\mathrm{mg} / \mathrm{kg}$ & Route & Time before testing, min & \\
9 & GBR 12909 & $5,10,20$ & IP & 20 & 12 \\
10 & Nisoxetine & $4,8,16$ & IP & 15 & \\
& GBR 12909 & 10 & IP & 20 & \\
\hline
\end{tabular}

received three administrations of AMPH (1 mg/kg, IP) spaced 2 days apart; rats with the lowest rate of calling on the third AMPH test were excluded from subsequent testing. Only the third AMPH test session was analyzed because the first two sessions are not necessarily indicative of a rat's subsequent USV response to AMPH (unpublished observation). In total, 52 rats (out of 126 rats that underwent screening) were excluded on this basis.

Drug testing All experiments featured a fully parametric within-subject design, whereby each rat was tested once under each drug/dose condition (see Table 1 for details). Thus, in Experiments 1-7, rats received all combinations of pretreatment and treatment drugs including all vehicle controls. After the pretreatment time interval had elapsed, each rat was injected with saline or AMPH $(1 \mathrm{mg} / \mathrm{kg}$, IP) and immediately placed in a test chamber and recorded for 20 min. Similarly, in Experiments 8-10, every rat was tested under the following conditions: vehicle, AMPH $(1 \mathrm{mg} / \mathrm{kg}$ positive control), and each dose of the drug(s) being tested. Here, recording sessions were of 20-min duration except for the GBR 12909 dose-response study (Experiment 8), where rats were tested for $40 \mathrm{~min}$. Within each experiment, the order of testing was counterbalanced as far as possible given the number of subjects. Test sessions were always spaced 2 days apart in order to minimize possible carry-over effects of the drugs.

\section{Drugs}

All test drugs, doses, routes of administration, and pretreatment/treatment time intervals are shown in Table 1. Drugs were: D-amphetamine sulfate (Sigma-Aldrich, Poole, UK); haloperidol and $\mathrm{S}(-)$-sulpiride (both from Sigma-Aldrich,
St. Louis, MO); pimozide, R(+)-SCH-23390 HCl, SCH $39166 \mathrm{HBr}$ (i.e., Ecopipam), raclopride, and risperidone (all from Tocris Bioscience, Ellisville, MO); clozapine, GBR 12909 2HCl, and ( \pm )-nisoxetine $\mathrm{HCl}$ (all from the NIMH Chemical Synthesis and Drug Supply Program). Doses of the different compounds refer to the form indicated above. GBR 12909 was administered in a volume of $2 \mathrm{ml} / \mathrm{kg}$; all other drugs were administered in a volume of $1 \mathrm{ml} / \mathrm{kg}$. Sulpiride was dissolved in a few drops of glacial acetic acid and diluted with sterile saline. Clozapine, GBR 12909, haloperidol, pimozide, and risperidone were dissolved in a $0.1 \mathrm{M}$ tartaric acid solution. All other drugs were dissolved in sterile saline. Drug vehicles were used for control injections. The $\mathrm{pH}$ of GBR 12909 could not be raised beyond 4.5 (with $\mathrm{NaOH}$ ) without precipitation. In case the lower $\mathrm{pH}$ affected call emission, each rat was tested twice with AMPH in Experiment 10, once with the standard drug solution and once with the same solution acidified with $\mathrm{HCl}$ to $\mathrm{pH} 4.5$. Since there was no difference in call rate or profile between the two AMPH tests, data from these tests were pooled for the remainder of the analysis.

\section{Behavioral recording}

USV recordings were conducted as previously described (Wright et al. 2012b). With the exception of Experiment 7 (see below), recordings took place in four clear Plexiglas experimental chambers (ENV-007CT, Med Associates, St Albans, VT), each of which was enclosed in a melamine compartment lined with sound-attenuating acoustic foam (Primacoustic, Port Coquitlam, British Columbia). A condenser ultrasound microphone (CM16/CMPA, Avisoft Bioacoustics, Berlin, Germany) was securely inserted through a small (5-cm diameter) hole located centrally in the top panel 
of each experimental chamber. Consequently, the microphones were $15-30 \mathrm{~cm}$ from rats during testing. Microphone signals were fed into an UltraSoundGate $416 \mathrm{H}$ data acquisition device (Avisoft Bioacoustics) with a sampling rate of $250-\mathrm{kHz}$ and $16-$ bit resolution.

For Experiment 7, USV recordings were made in rectangular, open-topped chambers $(58 \mathrm{~cm}$ long $\times 29 \mathrm{~cm}$ wide $\times$ $53 \mathrm{~cm}$ high) to allow simultaneous recording of USVs and locomotor activity, as previously described (Wright et al. 2012a). Two ultrasound microphones were secured inside each chamber at opposite corners, approximately $10 \mathrm{~cm}$ from the top (i.e., $40 \mathrm{~cm}$ above the floor). Soundattenuating acoustic foam enveloped the walls and extended $20 \mathrm{~cm}$ above the top of each chamber. A video tracking system (EthoVision v 3.0, Noldus Information Technology, Leesburg, VA, USA) measured locomotor activity (expressed as the total horizontal distance moved) during the second half (i.e., min 11-20) of the session to allow AMPH to take effect.

All lights were off during behavioral testing, except for Experiment 7, where far-red (wavelength $>650 \mathrm{~nm}$ ) illumination using a Kodak GBX-2 safelight filter (Vistek, Toronto, Ontario, Canada) provided darkroom lighting.

\section{Analysis and classification of ultrasonic vocalizations}

Acoustical analysis was performed using Avisoft SASLab Pro (version 5.1, Avisoft Bioacoustics), as previously described (Wright et al. 2012b). Calls were selected manually from spectrograms by an individual who was masked to the treatment condition. Each identified $50-\mathrm{kHz}$ call was classified into 1 of 14 distinct categories: complex, upward ramp, downward ramp, flat, short, split, step-up, step-down, multistep, trill, flat-trill combination, trill with jumps, or composite (see Wright et al. (2010) for criteria for call identification and classification, several examples of each call type, as well as descriptive statistics relating to acoustic parameters). A few representative $50-\mathrm{kHz}$ calls are shown in Fig. 1. This method of manual call selection has been validated by surgical devocalization, and classification is associated with

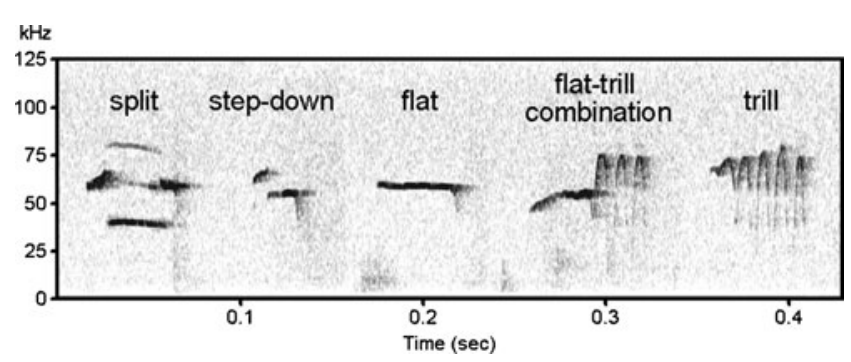

Fig. 1 Spectrogram containing individual $50-\mathrm{kHz}$ calls representative of the following subtypes (left to right): split, step-down, flat, flat-trill combination, and trill. See Wright et al. (2010) for additional examples of all fourteen $50-\mathrm{kHz}$ call subtypes high inter- and intra-rater reliability (Wright et al. 2010). The $22-\mathrm{kHz}$ calls were not analyzed since they were rarely observed in this study (specifically, one rat made two calls under sulpiride $40 \mathrm{mg} / \mathrm{kg}$ plus AMPH $1 \mathrm{mg} / \mathrm{kg}$ and another rat made 20 calls under sulpiride $80 \mathrm{mg} / \mathrm{kg}$ plus $\mathrm{AMPH}$ $1 \mathrm{mg} / \mathrm{kg}$ ).

Data analysis and statistics

Data were analyzed using commercial software (Systat v11, SPSS, Chicago, IL; GraphPad Prism 4, GraphPad Software, La Jolla, CA). For Experiments 1-7, USVs that occurred during minutes 12,14 , and 16 of the 20 -min session were counted and classified. These minutes were chosen since AMPH-induced calling becomes most pronounced within the 10-20 min time interval following AMPH administration (Wright et al. 2010). In Experiment 8, data throughout the entire $40 \mathrm{~min}$ session were analyzed. Finally, for Experiments 9 and 10, USV analysis was performed for minutes 3 , 8,13 , and 18 of the 20 -min session (i.e., we chose 4 min of time-sampling and spread it evenly across the session). One rat was removed for the call subtype analysis in Experiment 2 ( $\mathrm{SCH} 39166)$ because it only emitted one call at the highest dose, making it an extreme outlier when evaluating the percentage data. Repeated-measures ANOVA was performed to determine the effect of the within-subjects factors "pretreatment" and "treatment," where appropriate. Pairwise comparisons were performed using paired $t$ tests or Wilcoxon tests; the choice of test depended on the distribution of the raw data. ANOVA $p$ values were subject to the Huynh-Feldt correction, where appropriate. Multiple comparisons relating to the call rate data were subject to HolmBonferroni corrections, except where stated. However, for the call subtype analysis, pairwise comparisons were performed using uncorrected tests, in order to maintain statistical power. For all analyses, a two-tailed $p$ value $<5 \%$ (after any correction) was considered significant.

\section{Results}

Note that statistically significant results were found for certain of the less frequent call subtypes, but they were not consistently observed across doses or drugs of the same class and are likely to be false-positives; hence, these results are not reported here.

Experiments 1 and 2: effects of the D1 antagonists $\mathrm{SCH}$ 23390 and $\mathrm{SCH} 39166$

As expected, AMPH given alone (i.e., with vehicle pretreatment) greatly increased the rate of $50-\mathrm{kHz}$ calling (Wilcoxon $Z=2.80$ and 3.06, both $p<0.01$; Fig. 2a, b). The call rate under 


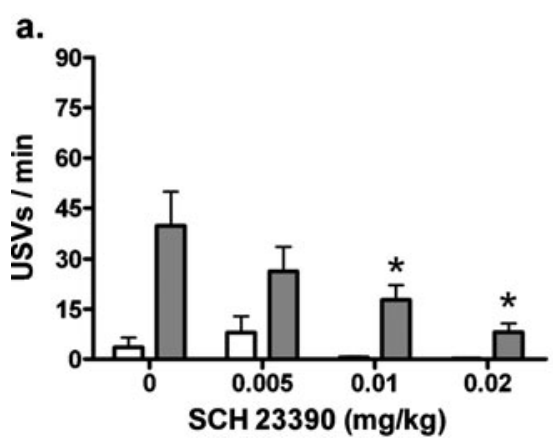

Fig. 2 Experiments 1 and 2: The $\mathrm{D}_{1}$ antagonists SCH 23390 (a) and SCH 39166 (b) dose-dependently inhibited the call rate under AMPH. The $y$ axes represent mean + SEM calls/min. Each rat was tested under all pretreatment/treatment conditions (SCH 23390 group $n=10 ; \mathrm{SCH}$

AMPH was dose-dependently reduced by both SCH 23390 and $\mathrm{SCH} 39166$, with significant effects at the two higher doses (SCH 23390, Wilcoxon $Z=2.70$ and 2.70, $p<0.05 ; \mathrm{SCH}$ 39166, Wilcoxon $Z=2.90$ and 3.06, $p<0.01$; Fig. 2). Each antagonist, given alone, tended to suppress calling below the already-low baseline call rate, but a statistically significant inhibitory effect only occurred at the highest dose of $\mathrm{SCH}$ 39166 (Wilcoxon $Z=2.80, p<0.05$; Fig. $2 b$ ).

Higher doses of the D1-like antagonists also significantly affected the call profile. More specifically, the proportion of trill calls under AMPH was dose-dependently suppressed by both SCH $23390(0.01$ and $0.02 \mathrm{mg} / \mathrm{kg}$ versus vehicle, Wilcoxon $Z=2.29$ and 2.19, $p<0.05$; Fig. 3a) and $\mathrm{SCH}$ $39166(0.3 \mathrm{mg} / \mathrm{kg}$ versus vehicle, Wilcoxon $Z=2.52, p<$ 0.05; Fig. 3c). In addition, SCH 39166 significantly enhanced the proportion of flat calls under AMPH at the highest dose tested (i.e., $0.3 \mathrm{mg} / \mathrm{kg}$ ) (Wilcoxon $Z=2.38, p<0.05$; Fig. 3d). Although the proportion of flat calls appeared to be enhanced by $\mathrm{SCH} 23390$, this failed to reach statistical significance (Fig. 3b). No other call subtype was significantly altered.

Experiments 3-5: effects of the $\mathrm{D}_{2}$ antagonists haloperidol, sulpiride, and raclopride

Call rate under $A M P H$ Haloperidol, at both doses tested $(0.1$ and $0.2 \mathrm{mg} / \mathrm{kg})$, significantly inhibited calling following AMPH administration (respectively, Wilcoxon $Z=2.31$, $p<0.05$, and 3.06, $p<0.01$; Fig. 4a); sulpiride (20 and $40 \mathrm{mg} / \mathrm{kg}$ ), in contrast, had no effect (Fig. 4b). Sulpiride was tested again at a higher dose (Experiment 5), this time in parallel with raclopride (Fig. 4c). Sulpiride again failed to affect the rate of calling after AMPH treatment, whereas raclopride behaved similarly to haloperidol, inhibiting 50 $\mathrm{kHz}$ calling at all doses tested (Wilcoxon $Z=3.06,2.98$, and $3.06, p<0.01$; Fig. $4 c$ ).

Call rate after antagonist alone Haloperidol did not alter the call rate after saline challenge (Fig. 4a); here, however, b.

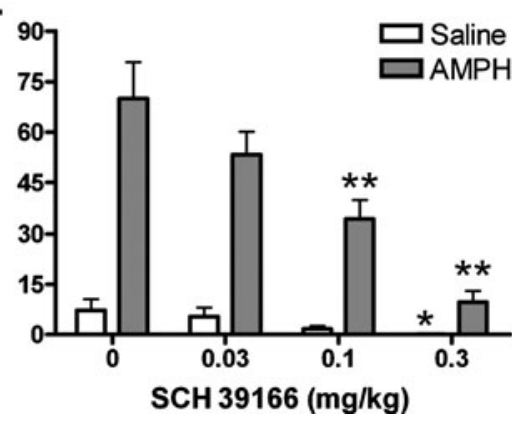

39166 group $n=12)$. SCH 39166 alone also decreased the call rate at the highest dose tested (i.e., $0.3 \mathrm{mg} / \mathrm{kg}$ ). ${ }^{*} p<0.05,{ }^{* *} p<0.01$ versus corresponding vehicle pretreatment condition

control call rates were very low (i.e., $<3$ calls $/ \mathrm{min}$ ). Sulpiride, tested alone, significantly reduced calling at only one dose $(40 \mathrm{mg} / \mathrm{kg}$ Wilcoxon $Z=2.28, p<0.05$; Fig. $4 \mathrm{c})$, and this apparent effect was not replicated across experiments

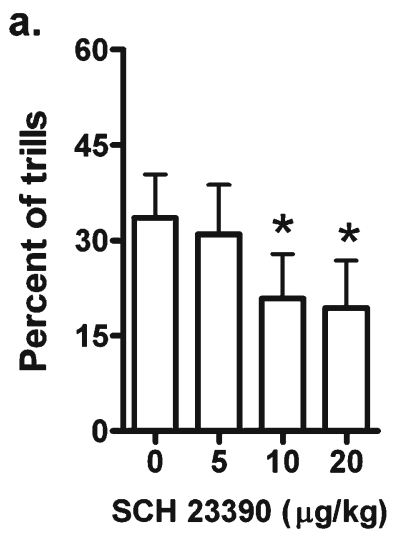

b.

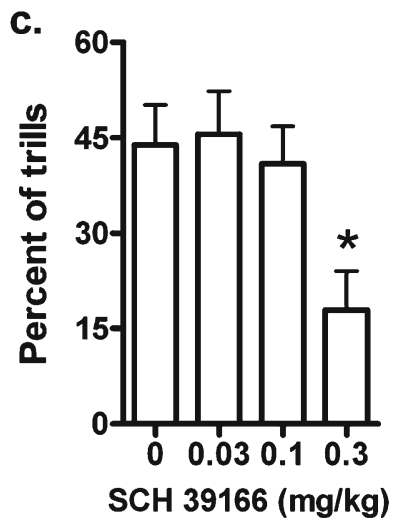

d.

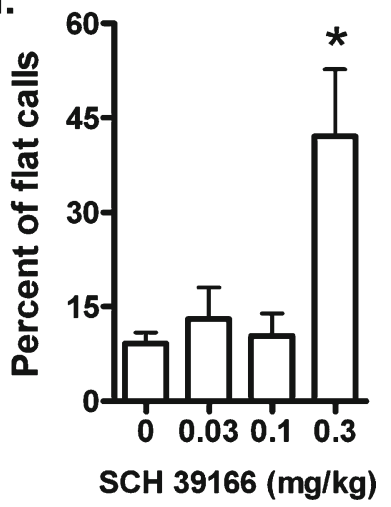

Fig. 3 Experiments 1 and 2: Pretreatment with the $D_{1}$ antagonists SCH 23390 (a) and SCH 39166 (c) before AMPH dose-dependently reduced the percent of trill calls. SCH 39166 also increased the percent of flat calls at the highest dose tested $(0.3 \mathrm{mg} / \mathrm{kg})(\mathbf{d})$. The apparent increase in the percent of flat calls with SCH 23390 was statistically non-significant (b). Each rat was tested under all pretreatment/treatment conditions (SCH 23390 group $n=10$; SCH 39166 group $n=12$ ). $* p<0.05$ versus vehicle control 

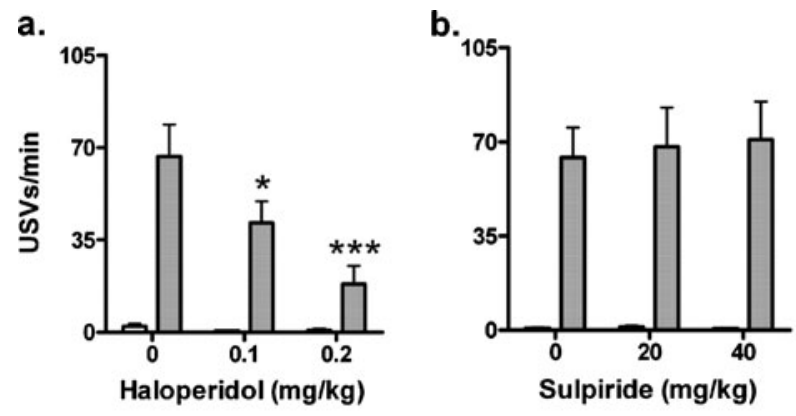

c.

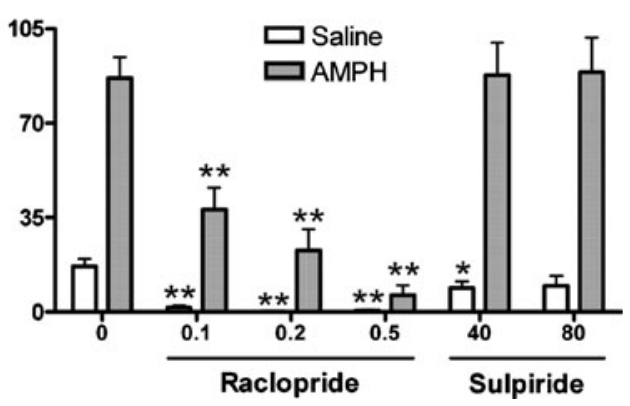

Fig. 4 Experiments 3-5: Haloperidol (a) and raclopride (c) dosedependently inhibited USV emission under AMPH (grey bars) at all doses tested, while sulpiride (b, c) was ineffective. Raclopride (c) also reduced the call rate following saline treatment (open bars). Sulpiride

(i.e., Experiment 4 versus 5; see Fig. $4 \mathrm{~b}$ versus c). In contrast, raclopride tested alone significantly inhibited the call rate at all doses tested $(0.1,0.2$, and $0.5 \mathrm{mg} / \mathrm{kg}$ versus vehicle, Wilcoxon $Z=2.85,3.06$, and 3.06, $p<0.01$; Fig. $4 c$ ).

Call profile Haloperidol and raclopride dose-dependently suppressed the proportion of trill calls following AMPH challenge (haloperidol $0.2 \mathrm{mg} / \mathrm{kg}$ versus vehicle, Wilcoxon $Z=2.51, p<0.05$; raclopride $0.5 \mathrm{mg} / \mathrm{kg}$ versus vehicle, Wilcoxon $Z=2.1, \mathrm{p}<0.05$; Fig. 5a, c). This effect appeared less potent than the rate-inhibiting effect (Fig. $4 \mathrm{a}, \mathrm{c}$ ). Raclopride $(0.2 \mathrm{mg} / \mathrm{kg})$ also increased the proportion of flat calls under AMPH (mean \pm SEM percent of flat calls following pretreatment with vehicle versus $0.2 \mathrm{mg} / \mathrm{kg}$ raclopride, $12.7 \pm 2.9$ versus $32.8 \pm 4.5$; Wilcoxon $Z=2.5, p<0.05$ ). In contrast, sulpiride marginally increased the proportion of trill calls at $40 \mathrm{mg} / \mathrm{kg}$ in Experiment 5 (Wilcoxon $Z=2.19, p<0.05$; Fig. 5c) but not in Experiment 4 (Fig. 5b).

Experiment 6: effects of pimozide and the atypical antipsychotics clozapine and risperidone

Pimozide, clozapine, and risperidone were all tested at a single, high dose. All three antagonists markedly inhibited only modestly reduced the drug-free call rate at $40 \mathrm{mg} / \mathrm{kg}$ in Experiment 5 (c). Each rat was tested under all pretreatment/treatment conditions ( $n=12$ rats per experiment). ${ }^{*} p<0.05,{ }^{* *} p<0.01,{ }^{* * *} p<0.001$ versus corresponding vehicle pretreatment

both USV after saline treatment and AMPH-induced USV production (see Fig. 6). Despite low rates of calling, call subtype analysis revealed that pimozide significantly reduced the proportion of trill calls under AMPH (mean \pm SEM percent of trills: vehicle versus pimozide, $36.4 \pm 6.5$ versus $13.3 \pm 11.4$, respectively; Wilcoxon $Z=2.37, p<0.05$ ).

Experiment 7: effect of high-dose sulpiride on $50-\mathrm{kHz}$ USVs and locomotor activity

Sulpiride $(80 \mathrm{mg} / \mathrm{kg})$ significantly decreased AMPHinduced locomotor activity (ANOVA pretreatment $\times$ treatment interaction, $F_{1,15}=14.85, p<0.01$; Fig. 7). Sulpiride also reduced locomotor activity when given alone $\left(t_{15}=\right.$ 3.39, $p<0.01$; Fig. 7a). In contrast, sulpiride exerted no detectable effect on either the call rate (Fig. $7 b$ ) or profile (not shown).

Experiments 8-10: effect of GBR 12909 and nisoxetine, alone and in combination

Unlike AMPH, neither GBR 12909 nor nisoxetine significantly promoted $50-\mathrm{kHz}$ calling at any dose tested; all comparisons were statistically non-significant after Holm-
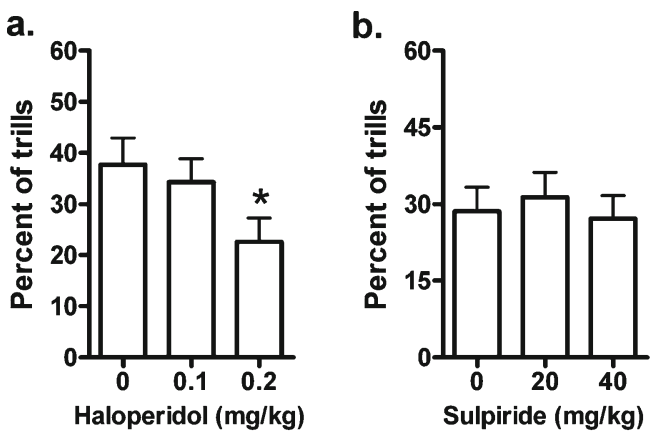

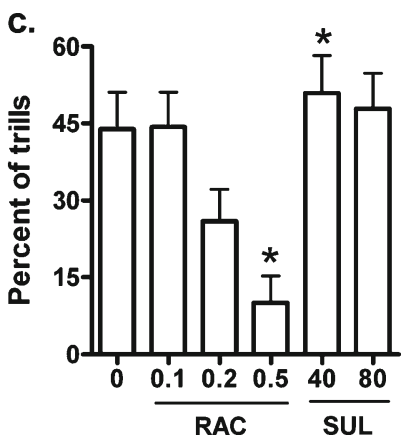

Fig. 5 Experiments 3 and 5: Haloperidol (a) and raclopride $(R A C)$ (c) suppressed trills (as a proportion of all $50-\mathrm{kHz}$ calls) following AMPH administration at the highest doses tested. Sulpiride $(S U L)$, in contrast, was largely ineffective $(\mathbf{b}, \mathbf{c})$, except for an increase in the proportion of trills at $40 \mathrm{mg} / \mathrm{kg}$ in Experiment 5 (c). Each rat was tested under all pretreatment/treatment conditions $\left(n=12\right.$ rats per experiment). ${ }^{*} p<$ 0.05 versus vehicle control 


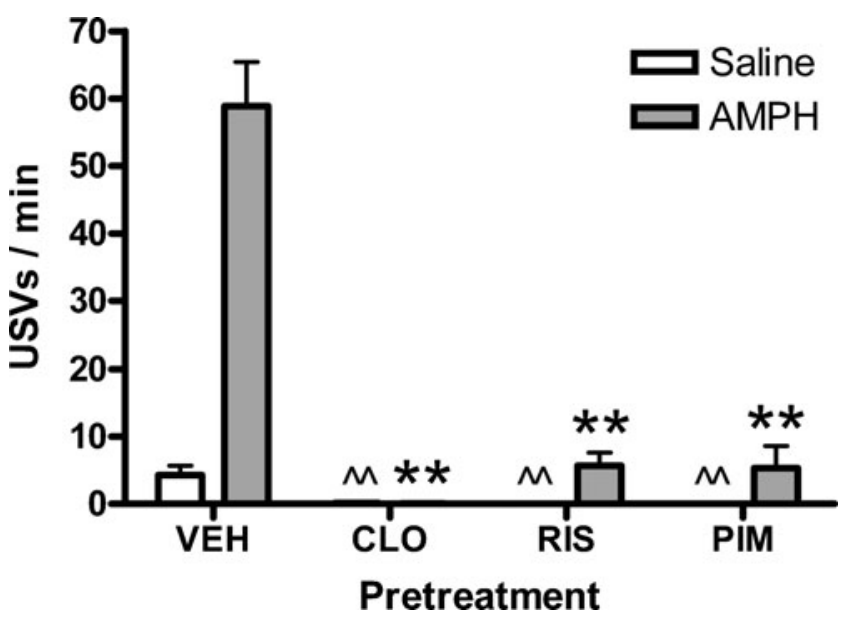

Fig. 6 Experiment 6: Single doses of clozapine (4 mg/kg, SC; CLO), risperidone $(0.5 \mathrm{mg} / \mathrm{kg}, \mathrm{SC} ; R I S)$, and pimozide $(1 \mathrm{mg} / \mathrm{kg}$, IP; PIM), all markedly reduced the $50-\mathrm{kHz}$ call rate under saline (open bars) and AMPH $1 \mathrm{mg} / \mathrm{kg}$ IP (grey bars). Each rat was tested under all pretreatment/treatment conditions ( $n=12$ rats). ${ }^{\wedge} p p<0.01$ versus vehicle/saline control, ${ }^{* *} p<0.01$ versus vehicle/AMPH control

Bonferroni correction (Experiments 8 and 9, respectively; Fig. 8a, b). In Experiment 8, GBR 12909 tended to increase the call rate at $10 \mathrm{mg} / \mathrm{kg}$, especially in the first half of the $40-$ min session, i.e., time 20-40 min post-injection (Supplemental Fig. S1). Accordingly, this shorter post-injection interval was used when this drug was retested in Experiment 10. Here, selected doses of GBR 12909 (i.e., $10 \mathrm{mg} / \mathrm{kg}$ ) and nisoxetine (i.e., $12 \mathrm{mg} / \mathrm{kg}$ ) were administered, not only alone but also in combination; there was still no significant enhancement (or suppression) of call rate (Fig. 8c). Notably, the $10 \mathrm{mg} / \mathrm{kg}$ dose of GBR 12909 which appeared to increase calling in Experiment 8 no longer showed such a trend (Fig. 8c). a.

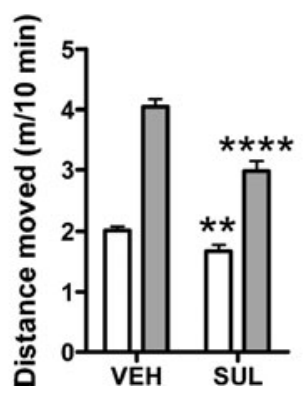

b.

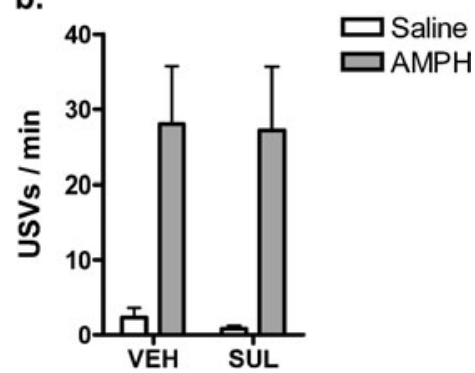

Fig. 7 Experiment 7: Sulpiride (SUL; $80 \mathrm{mg} / \mathrm{kg}, \mathrm{SC})$ significantly inhibited AMPH-induced locomotor activity (panel a) (ANOVA pretreatment $\times$ treatment interaction $\left.-F_{1,15}=14.85, p<0.01\right)$ but produced no detectable effect on the rate of USV emission (panel b). The $y$ axes represent mean + SEM total horizontal distance (meters) travelled (panel a) or the $50-\mathrm{kHz}$ call rate (panel b), following administration of saline (open bars) or AMPH (grey bars). ${ }^{* *} p<0.01, * * * * p<0.0001$ versus corresponding vehicle $(V E H)$ control
The reuptake inhibitors, given alone or in combination, failed to mimic the effect of AMPH on the call profile. For example, in Experiment 10, AMPH significantly increased the relative prevalence of trill calls, but neither GBR 12909, nor nisoxetine, or their combination showed this effect (mean \pm SEM percent trills: vehicle versus AMPH, 22.9 \pm 5.2 versus $46.3 \pm 6.7$, respectively; Wilcoxon $Z=2.58, p<$ 0.01 ). Conversely, a significant reduction in the proportion of flat calls was observed following the co-administration of GBR 12909 and nisoxetine, yet AMPH unexpectedly did not reduce the proportion of flat calls in this particular experiment (mean \pm SEM percent flat calls: vehicle versus GBR $12909+$ nisoxetine, $21.9 \pm 6.3$ versus $10.3 \pm 6.0$, respectively; Wilcoxon $Z=2.67, p<0.01$ ).

\section{Discussion}

The present study provides the first evidence that D1-like and D2-like receptor antagonists modulate the effects of systemic AMPH administration on the $50-\mathrm{kHz}$ call rate and profile. Exceptionally, sulpiride, which is a D2-like antagonist with atypical antipsychotic features, consistently failed to affect USV emission. In addition, neither GBR 12909 (DAT inhibitor) nor nisoxetine (NET inhibitor), or their combination, mimicked the effects of AMPH on USV production. Below, we argue that both D1-like and D2-like DA receptors play a critical role in $50-\mathrm{kHz}$ USV emission, and we suggest mechanisms contributing to sulpiride's lack of effect. We subsequently review antagonist-induced USVs suppression in the context of other behavioral and clinical effects of the same drugs. Finally, we discuss whether enhanced DA or NA transmission is sufficient to promote USV emission.

D1 dopaminergic receptor antagonism

The D1-like antagonists SCH 23390 and SCH 39166 dosedependently inhibited the $50-\mathrm{kHz}$ call rate and the percentage of trill calls following AMPH challenge; both antagonists also tended to reduce the call rate below control (i.e., drug-free) levels, although a significant reduction was only seen at the highest dose of SCH 39166. SCH 23390 and SCH 39166 both bind with high affinity to D1 and D5 receptors, with negligible affinity for D2-like receptors (i.e., D2, D3, and D4) (Tice et al. 1994). While SCH 23390 also has considerable affinity for serotonin receptors, namely $5 \mathrm{HT}_{2}$ and $5 \mathrm{HT}_{1 \mathrm{C}}$ (Bischoff et al. 1986; Nicklaus et al. 1988), SCH 39166 does not (Alburges et al. 1992; McQuade et al. 1991a, b; Wamsley et al. 1991). To our knowledge, these drugs do not have any other significant off-target effects. Thus, DA D1-like receptors appear critical to the USV-altering effects of systemic AMPH and may also regulate USV emission in the absence of this drug. 


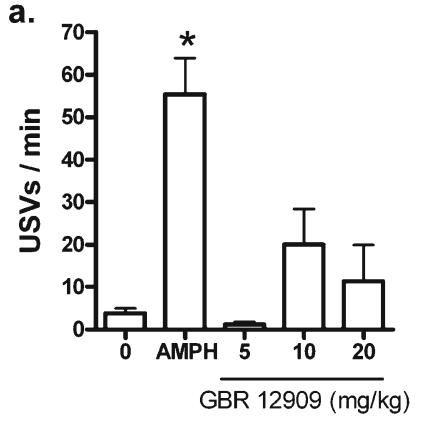

Fig. 8 Experiments 8-10: GBR 12909 (a) and nisoxetine (b) failed to significantly promote $50-\mathrm{kHz}$ calling at any dose tested. Panel c shows that single doses of GBR 12909 (GBR, $10 \mathrm{mg} / \mathrm{kg} \mathrm{IP})$ and nisoxetine

\section{D2 dopaminergic receptor antagonism}

All six D2-like antagonists, with the notable exception of sulpiride, markedly inhibited or abolished the stimulatory effect of AMPH on call rate. Additionally, haloperidol and raclopride dose-dependently decreased the proportion of trill calls under AMPH. The latter finding is in line with previous studies showing a reduction in the proportion of FM calls in response to sexual odors following systemic haloperidol pretreatment (Ciucci et al. 2007, 2009). It appears likely that DA transmission through D2-like receptors is critical for both the call rate and profile following AMPH, since several possibilities exist as to why sulpiride is anomalous:

1. Sulpiride may exert an additional (as yet unidentified) action which functionally counteracts D2 receptor blockade. Indeed, studies with muscarinic cholinergic and adenosine $\mathrm{A} 2 \mathrm{~A}$ receptor antagonists have provided such a precedent, in that these drugs can reverse the behavioral effects of DA receptor blockade (Collins et al. 2012; Morpurgo and Theobald 1964).

2. The phenomenon of D2-like receptor heteromerization (Maggio et al. 2009) suggests another plausible mechanism by which sulpiride might exert functional effects that are distinct from those of other D2-like antagonists.

3. It is unlikely that our doses of sulpiride were insufficient to antagonize USV emission, since comparable or even lower doses have proven effective in a number of DAdependent behavioral assays, i.e., apomorphine hyperactivity and stereotypy (de Paulis et al. 1985), the AMPH cue (Nielsen and Andersen 1992; Nielsen and Jepsen 1985), conditioned place preference (CPP) induced by food or testosterone (Guyon et al. 1993; Schroeder and Packard 2000), and intravenous selfadministration of nicotine or cocaine (Sorge and Clarke 2009). Importantly, a high dose of sulpiride that failed to affect the call rate did, at the same time, reduce AMPHinduced hyperactivity (present study-Experiment 7); the latter effect is consistent with previous findings

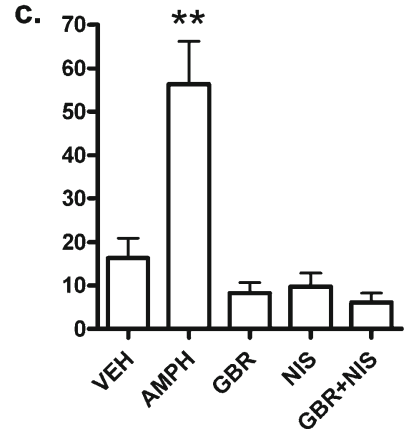

$(N I S, 12 \mathrm{mg} / \mathrm{kg} \mathrm{IP})$, given either alone or even in combination $(G B R+$ $N I S)$, still failed to modify the call rate detectably (c). ${ }^{*} p<0.05, * * p<0.01$ versus vehicle control $(\mathrm{VEH})$

(Ljungberg and Ungerstedt 1985; Moore and Kenyon 1994; Sharp et al. 1986; White et al. 1992).

4. Sulpiride, in contrast to many D2-like antagonists, possesses considerably lower affinity at D4 compared with D2 and D3 receptors (Rondou et al. 2010; Seeman et al. 1997; Seeman and Van Tol 1994). However, it is unlikely that D4 receptors are critical to USV emission since raclopride (Experiment 5) markedly reduced USVs despite also having very low affinity at D4 receptors (Seeman and Van Tol 1994).

5. The "atypical" antipsychotic properties of sulpiride do not appear related to its lack of effect on USV emission, since the atypical drugs clozapine and risperidone clearly inhibited calling.

6. Since D2-like antagonists tend to be pharmacologically non-selective (Jafari et al. 2012), it is conceivable that all the D2-like antagonists tested, except for sulpiride, fortuitously suppressed calling through some shared non-DAergic mechanism. However, this possibility seems remote since the compounds were drawn from multiple, structurally heterogeneous chemical classes (Jafari et al. 2012), and we are unaware of any such shared receptor candidate. Notably, $\alpha 1$ adrenergic receptor blockade abolishes AMPH-induced calling (Wright et al. 2012b), but some DA antagonists (e.g., raclopride) lack significant affinity for this receptor (Hall et al. 1986; Ishiwata et al. 2001; Ogren et al. 1986).

Behavioral mechanisms

The USV-related effects produced by the DA-like antagonists in the present study are summarized in Table 2, together with several other behavioral effects of the same drugs reported in the literature. Antagonist doses that inhibited saline- or AMPH-induced USVs frequently overlapped with those affecting other behavioral measures. However, as discussed below, no particular behavioral measure matched our USV findings completely. 


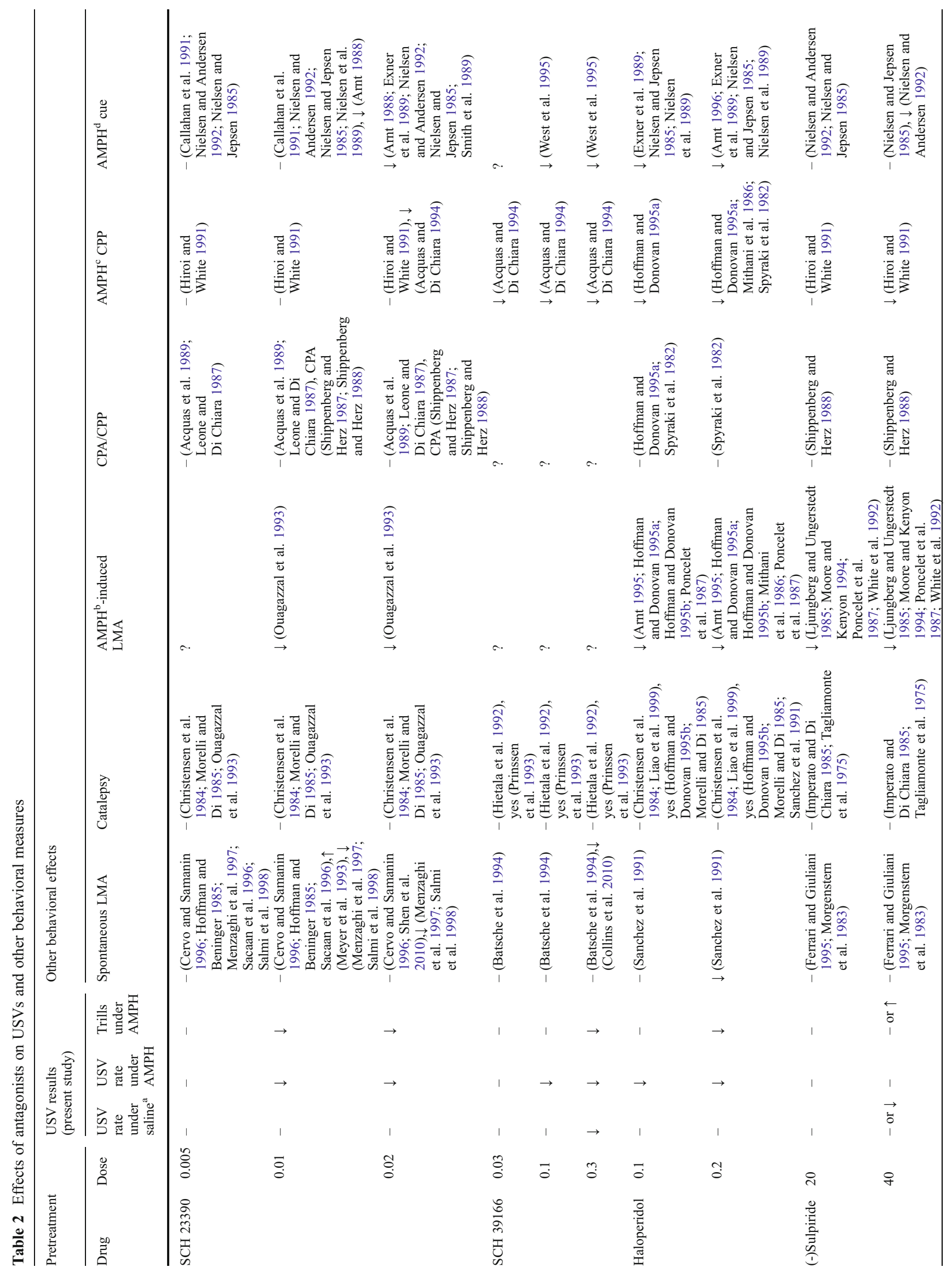




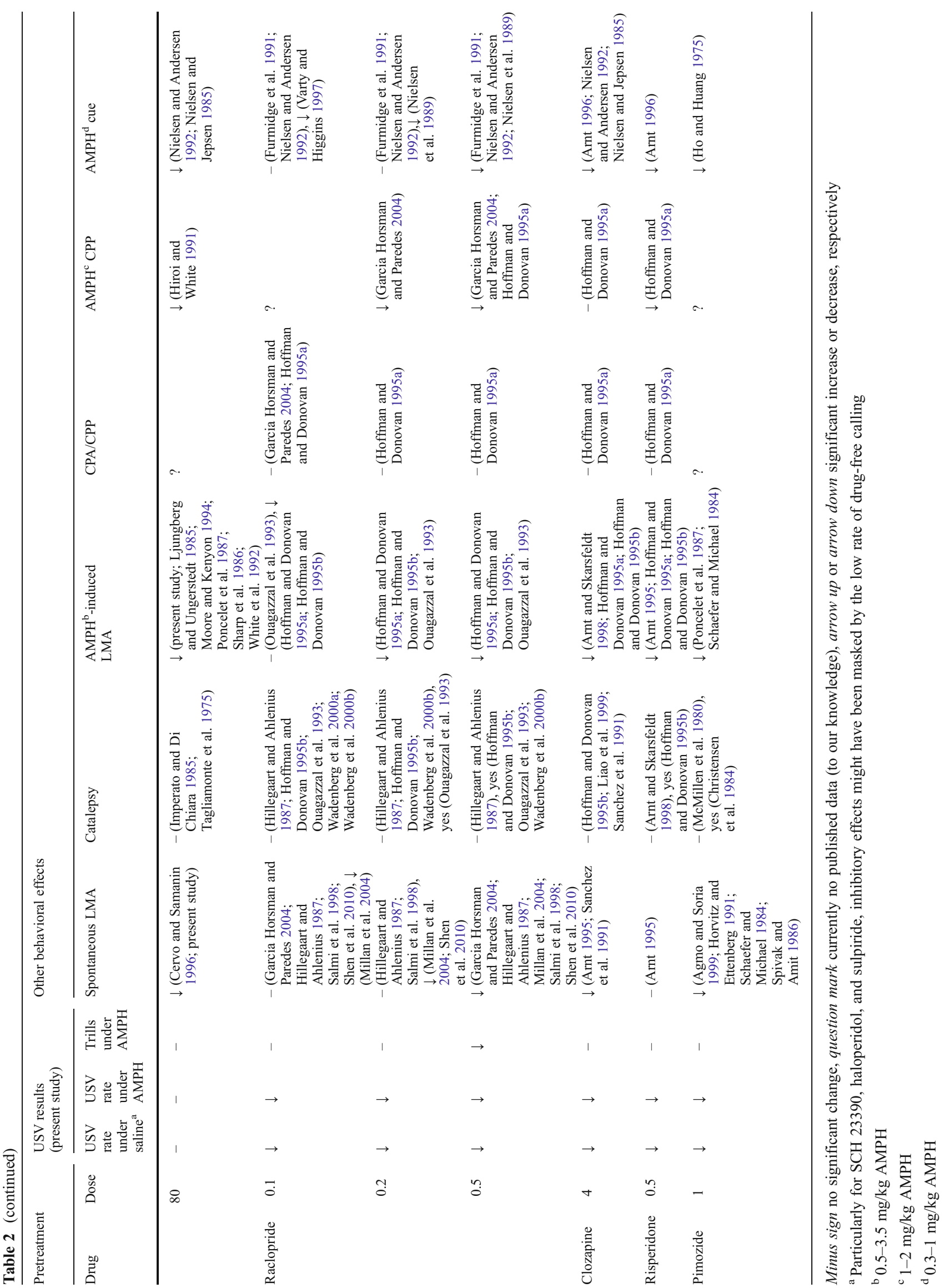


USVS versus motor function Several DA antagonists (i.e., haloperidol, clozapine, risperidone, pimozide) inhibited USV emission at doses expected to markedly suppress drug-free or AMPH-associated locomotion (Table 2). In general, however, there was no consistent relationship between motor impairment and USV emission. In particular, raclopride inhibited drug-free USV production even at low doses which tend not to inhibit locomotion, and conversely, sulpiride inhibited drug-free and AMPH-induced locomotion without detectably affecting USV production (Table 2).

AMPH cue The discriminative stimulus effects of AMPH are of particular interest since they serve to model the drug's subjective effects in humans (Brauer et al. 1997). The USVstimulatory and cue effects of AMPH appear similarly affected by our D1 and D2 antagonists, but only the latter is attenuated by sulpiride (see Table 2 for references).

USVS versus reward/aversion Since $50-\mathrm{kHz}$ USVs have been proposed as a measure of drug reward, it is potentially informative to compare our results with published work using the conventional reward measure of CPP, while acknowledging that the latter reflects conditioned rather than unconditioned drug effects. Both D1 antagonists appeared to inhibit $50-\mathrm{kHz}$ calling under saline treatment, allowing for the low rate of drug-free calling. However, it is unclear whether D1 receptor blockade reliably produces a conditioned place aversion (CPA) in rats (Table 2), since D1 antagonist effects are either mixed ( $\mathrm{SCH} 23390)$ or unreported (SCH 39166). In contrast, D2-like antagonists consistently fail to produce a CPP or CPA in adult rats (Tzschentke 1998). The lack of D2 antagonist-induced CPP or CPA does not appear to reflect a learning or memory deficit, since D2 receptor blockers do not inhibit the acquisition of all types of CPP or CPA (Tzschentke 1998). Thus, D2 receptor antagonists appear neutral in the CPP/CPA test, yet all our D2 receptor antagonists (with the exception of sulpiride) tended to inhibit calling under saline treatment.

The acquisition of AMPH CPP is inhibited by D1 and D2 receptor antagonists, according to most reports (Table 2). However, our USV findings reveal two striking differences: (1) sulpiride did not inhibit AMPH-induced calling (present study), whereas it inhibited AMPH CPP (Hiroi and White 1991), and (2) clozapine abolished AMPH-induced calling, yet failed to inhibit AMPH CPP (Hoffman and Donovan 1995a). Importantly, these studies employed comparable doses of antagonist and AMPH.

USVS versus affect Although classic antipsychotics (e.g., haloperidol) do not produce a CPA in rats (see above), they often produce dysphoria in human subjects (Emerich and Sanberg 1991; Voruganti and Awad 2004). Atypical antipsychotics, in contrast, appear far less commonly associated with dysphoria, as evidenced by sulpiride, clozapine, and risperidone (Mehta et al. 1999; Potvin et al. 2003; Voruganti et al. 2000). Although the latter two drugs produced profound alterations in USV emission in the present study, circulating levels of these three DA antagonists probably far exceeded the clinical range.

USVs versus AMPH euphoria The dose of AMPH employed in the present study (i.e., $1 \mathrm{mg} / \mathrm{kg}$ ) appears comparable to euphorigenic doses in human studies (Grilly and Loveland 2001). FM 50-kHz ultrasonic vocalizations (USVs) have been proposed to reflect hedonia (Burgdorf and Moskal 2009), and the trill subtype in particular appears most closely associated with rewarding doses of AMPH and cocaine (Wright et al. 2010, 2012b). Although trill calls following AMPH were preferentially inhibited by both D1-like and some D2-like (i.e., haloperidol, raclopride, and pimozide) antagonists in the present study, it is important to note that animal and human studies do not strongly support a role for DA in hedonia but rather in incentive salience or "wanting" (Brauer and de Wit 1997; Leyton et al. 2005, 2007; Smith et al. 2011). Therefore, in view of the present findings, we speculate that emission of FM $50-\mathrm{kHz}$ calls, and trills in particular, may relate to incentive salience rather than hedonia. Flat calls, in contrast to trill calls, were significantly increased in relative terms by certain doses of SCH 39166 and raclopride, possibly as a consequence of trill call suppression. Flat calls have been proposed to have a social-coordinating function unrelated to positive affect (Wohr et al. 2008).

\section{Dopamine and noradrenaline reuptake inhibitors}

AMPH and cocaine, which increase both DA and NA transmission (McKittrick and Abercrombie 2007), enhance USV production and modulate the call profile (Wright et al. 2010, $2012 b$ ). The results of the present study together with previous findings (Wright et al. 2012b) suggested that both DA and NA transmission are necessary for the observed effects of AMPH on USV emission. The question of sufficiency was addressed by subsequently examining whether the selective DAT and NET inhibitors GBR 12909 (Andersen 1989) and nisoxetine (Wong et al. 1982; Wong and Bymaster 1976), respectively, could mimic the USV effects of AMPH or cocaine. Neither GBR 12909 nor nisoxetine, alone or in combination, mimicked the effect of AMPH on the call rate or profile in the present study. At doses tested here, GBR 12909 would be expected to elevate extracellular DA, and co-administration of a NET blocker would likely potentiate this increase (Carboni et al. 2006). To our knowledge, there are no studies directly examining extracellular NA following nisoxetine administration in rats. Instead, the doses of nisoxetine were chosen based on their ability to generalize to the cues produced by the non-selective $\beta$-adrenergic 
agonist isoproterenol (Crissman and O'Donnell 2002) and the NET blocker reboxetine (Millan and Dekeyne 2007); the latter drug produces a marked increase in extracellular levels of NA (Dekeyne et al. 2001).

GBR 12909 and nisoxetine, unlike AMPH, appear to exert their behavioral effects solely through transmitter reuptake inhibition. We have previously found that the DA/NA reuptake blocker cocaine moderately stimulated 50-kHz calling, while mimicking AMPH's ability to promote trill calls preferentially (Wright et al. 2012b). It is unclear why GBR 12909 and nisoxetine failed to exert either of these effects; here, cocaine's ability to inhibit the 5-HT reuptake transporter (Wall et al. 1995) or enhance exocytotic DA release (Ramsson et al. 2011) may be relevant.

\section{Limitations}

Adult rats exhibit large variability in their USV response to systemic AMPH (Taracha et al. 2012; Wright et al. 2010). In order to examine drug effects on AMPH-induced calling, we identified low responders using an initial AMPH screen in most experiments. A substantial number of subjects were then excluded, resulting in a selected population that may differ in other behavioral or neurochemical respects (Burgdorf et al. 2008). Notably, the failure of sulpiride to modify the call rate or profile was independent of whether rats were screened or not (compare Experiment 5 with Experiments 4 and 7). The present method of selecting adult rats based on their acute response to AMPH helps to address the issue of low baseline call rates and high individual differences. Other approaches include selective breeding (Burgdorf et al. 2008) and possibly through prior social manipulations (Vivian and Miczek 1991).

Due to the labor-intensive nature of this type of USV analysis, only a small fraction of the entire session (i.e., 3 or $4 \mathrm{~min}$ ) was time-sampled for most experiments. It is possible that USV effects outside our chosen time intervals were missed. This method of time-sampling therefore limits interpretation of the present findings.

Finally, certain drugs, namely sulpiride, GBR 12909, and nisoxetine, exerted no discernable effects on USV emission. In the case of sulpiride, we performed an additional experiment (Experiment 7) where USVs and locomotion were assessed simultaneously. However, the negative findings with GBR 12909 and nisoxetine (or their combination) were not followed up with additional behavioral testing. While GBR 12909 would be expected to stimulate locomotor activity at all the doses tested (Hooks et al. 1994; Powell et al. 2001), nisoxetine does not appear to affect this measure in adult rats (Davids et al. 2002; Powell et al. 2001). The lack of positive controls in Experiments 8-10 is a limiting factor when interpreting these results.

\section{Conclusion}

USVs are a potentially rich source of information about the rat's subjective state. The present study furthers our understanding of the neurochemical substrates regulating USV production in adult rats. DA transmission appears critical for the $50-\mathrm{kHz}$ USV response to systemic AMPH, since antagonism of either D1-like or D2-like receptors (with the notable exception of sulpiride) reversed the effects of AMPH on the call rate and profile. DA transmission also appears to modulate drug-free call emission. It appears that, although both DA and NA are required, inhibition of DA and NA reuptake per se is not sufficient to elicit an AMPHlike USV response.

Acknowledgments Supported by a Natural Science and Engineering Research Council of Canada (NSERC) discovery grant (155055, to P.B.S.C) and an NSERC Postgraduate Scholarship D (to J.M.W). The authors would like to acknowledge the NIMH Chemical Synthesis and Drug Supply Program for generously providing clozapine, GBR 12909 $2 \mathrm{HCl}$, and $( \pm)$-nisoxetine $\mathrm{HCl}$ for this study. P.B.S.C. is a member of the Center for Studies in Behavioral Neurobiology at Concordia University in Montreal. The authors have no financial relationship with the organization that sponsored this research. All experiments comply with the current laws of Canada.

\section{References}

Acquas E, Di Chiara G (1994) D1 receptor blockade stereospecifically impairs the acquisition of drug-conditioned place preference and place aversion. Behav Pharmacol 5:555-569

Acquas E, Carboni E, Leone P, Di CG (1989) SCH 23390 blocks drugconditioned place-preference and place-aversion: anhedonia (lack of reward) or apathy (lack of motivation) after dopamine-receptor blockade? Psychopharmacology (Berl) 99:151-155

Agmo A, Soria P (1999) The duration of the effects of a single administration of dopamine antagonists on ambulatory activity and motor coordination. J Neural Transm 106:219-227

Ahrens AM, Ma ST, Maier EY, Duvauchelle CL, Schallert T (2009) Repeated intravenous amphetamine exposure: rapid and persistent sensitization of $50-\mathrm{kHz}$ ultrasonic trill calls in rats. Behav Brain Res 197:205-209

Alburges ME, Hunt ME, McQuade RD, Wamsley JK (1992) D1receptor antagonists: comparison of $[3 \mathrm{H}] \mathrm{SCH} 39166$ to $[3 \mathrm{H}]$ SCH23390. J Chem Neuroanat 5:357-366

Andersen PH (1989) The dopamine inhibitor GBR 12909: selectivity and molecular mechanism of action. Eur J Pharmacol 166:493-504

Arnt J (1988) The discriminative stimulus properties of the D-1 agonist SK\&F 38393 and the D-2 agonist (-)-NPA are mediated by separate mechanisms. Life Sci 42:565-574

Arnt J (1995) Differential effects of classical and newer antipsychotics on the hypermotility induced by two dose levels of D-amphetamine. Eur J Pharmacol 283:55-62

Arnt J (1996) Inhibitory effects on the discriminative stimulus properties of D-amphetamine by classical and newer antipsychotics do not correlate with antipsychotic activity. Relation to effects on the reward system? Psychopharmacology (Berl) 124:117-125

Arnt J, Skarsfeldt T (1998) Do novel antipsychotics have similar pharmacological characteristics? A review of the evidence. Neuropsychopharmacology 18:63-101 
Batsche K, Ashby CR Jr, Lee C, Schwartz J, Wang RY (1994) The behavioral effects of the stereoisomers of 4-methylaminorex, a psychostimulant, in the rat. J Pharmacol Exp Ther 269:10291039

Bialy M, Kalata U, Nikolaev-Diak A, Nikolaev E (2010) D1 receptors involved in the acquisition of sexual experience in male rats. Behav Brain Res 206:166-176

Bischoff S, Heinrich M, Sonntag JM, Krauss J (1986) The D-1 dopamine receptor antagonist SCH 23390 also interacts potently with brain serotonin (5-HT2) receptors. Eur J Pharmacol 129:367-370

Brauer LH, de Wit H (1997) High dose pimozide does not block amphetamine-induced euphoria in normal volunteers. Pharmacol Biochem Behav 56:265-272

Brauer LH, Goudie AJ, de Wit H (1997) Dopamine ligands and the stimulus effects of amphetamine: animal models versus human laboratory data. Psychopharmacology (Berl) 130:2-13

Brudzynski SM (2007) Ultrasonic calls of rats as indicator variables of negative or positive states: acetylcholine-dopamine interaction and acoustic coding. Behav Brain Res 182:261-273

Brudzynski SM (2009) Communication of adult rats by ultrasonic vocalization: biological, sociobiological, and neuroscience approaches. ILAR J 50:43-50

Brudzynski SM, Komadoski M, St PJ (2012) Quinpirole-induced $50 \mathrm{kHz}$ ultrasonic vocalization in the rat: role of D2 and D3 dopamine receptors. Behav Brain Res 226:511-518

Burgdorf J, Moskal JR (2009) Frequency modulated $50 \mathrm{kHz}$ ultrasonic vocalizations reflect a positive emotional state in the rat: neural substrates and therapeutic implications. In: Brudzynski SM (ed) Handbook of mammalian vocalization. Academic, Oxford, pp 209-214

Burgdorf J, Wood PL, Kroes RA, Moskal JR, Panksepp J (2007) Neurobiology of $50-\mathrm{kHz}$ ultrasonic vocalizations in rats: electrode mapping, lesion, and pharmacology studies. Behav Brain Res $182: 274-283$

Burgdorf J, Panksepp J, Brudzynski SM, Beinfeld MC, Cromwell HC, Kroes RA et al (2008) The effects of selective breeding for differential rates of $50-\mathrm{kHz}$ ultrasonic vocalizations on emotional behavior in rats. Dev Psychobiol 51:34-46

Burgdorf J, Panksepp J, Moskal JR (2010) Frequency-modulated $50 \mathrm{kHz}$ ultrasonic vocalizations: a tool for uncovering the molecular substrates of positive affect. Neurosci Biobehav Rev 35:1831-1836

Callahan PM, Appel JB, Cunningham KA (1991) Dopamine D1 and D2 mediation of the discriminative stimulus properties of D-amphetamine and cocaine. Psychopharmacology (Berl) 103:50-55

Carboni E, Silvagni A, Vacca C, Di CG (2006) Cumulative effect of norepinephrine and dopamine carrier blockade on extracellular dopamine increase in the nucleus accumbens shell, bed nucleus of stria terminalis and prefrontal cortex. J Neurochem 96:473-481

Cervo L, Samanin R (1996) Effects of dopaminergic and glutamatergic receptor antagonists on the establishment and expression of conditioned locomotion to cocaine in rats. Brain Res 731:31-38

Christensen AV, Arnt J, Hyttel J, Larsen JJ, Svendsen O (1984) Pharmacological effects of a specific dopamine D-1 antagonist SCH 23390 in comparison with neuroleptics. Life Sci 34:1529-1540

Ciucci MR, Ma ST, Fox C, Kane JR, Ramig LO, Schallert T (2007) Qualitative changes in ultrasonic vocalization in rats after unilateral dopamine depletion or haloperidol: a preliminary study. Behav Brain Res 182:284-289

Ciucci MR, Ahrens AM, Ma ST, Kane JR, Windham EB, Woodlee MT, Schallert T (2009) Reduction of dopamine synaptic activity: degradation of $50-\mathrm{kHz}$ ultrasonic vocalization in rats. Behav Neurosci 123:328-336

Collins LE, Galtieri DJ, Collins P, Jones SK, Port RG, Paul NE, Hockemeyer J, Muller CE, Salamone JD (2010) Interactions between adenosine and dopamine receptor antagonists with different selectivity profiles: effects on locomotor activity. Behav Brain Res 211:148-155

Collins LE, Sager TN, Sams AG, Pennarola A, Port RG, Shahriari M, Salamone JD (2012) The novel adenosine A2A antagonist Lu AA47070 reverses the motor and motivational effects produced by dopamine D2 receptor blockade. Pharmacol Biochem Behav 100:498-505

Crissman AM, O'Donnell JM (2002) Effects of antidepressants in rats trained to discriminate centrally administered isoproterenol. J Pharmacol Exp Ther 302:606-611

Davids E, Zhang K, Kula NS, Tarazi FI, Baldessarini RJ (2002) Effects of norepinephrine and serotonin transporter inhibitors on hyperactivity induced by neonatal 6-hydroxydopamine lesioning in rats. J Pharmacol Exp Ther 301:1097-1102

de Paulis T, Kumar Y, Johansson L, Ramsby S, Florvall L, Hall H, Angeby-Moller K, Ogren SO (1985) Potential neuroleptic agents. 3 . Chemistry and antidopaminergic properties of substituted 6methoxysalicylamides. J Med Chem 28:1263-1269

Dekeyne A, Gobert A, Iob L, Cistarelli L, Melon C, Millan MJ (2001) Discriminative stimulus properties of the selective norepinephrine reuptake inhibitor, reboxetine, in rats. Psychopharmacology (Berl) 158:213-218

Emerich DF, Sanberg PR (1991) Neuroleptic dysphoria. Biol Psychiatry 29:201-203

Exner M, Furmidge LJ, White FJ, Clark D (1989) Inhibitory effects of partial D2 dopamine receptor agonists on the D-amphetamine discriminative cue. Behav Pharmacol 1:101-111

Ferrari F, Giuliani D (1995) Behavioural assessment in rats of the antipsychotic potential of the potent dopamine D2 receptor antagonist, (-)eticlopride. Pharmacol Res 31:261-267

Furmidge LJ, Exner M, Clark D (1991) Role of dopamine D1 and D2 receptors in mediating the D-amphetamine discriminative cue. Eur J Pharmacol 202:191-199

Garcia Horsman P, Paredes RG (2004) Dopamine antagonists do not block conditioned place preference induced by paced mating behavior in female rats. Behav Neurosci 118:356-364

Grilly DM, Loveland A (2001) What is a "low dose" of D-amphetamine for inducing behavioral effects in laboratory rats? Psychopharmacology (Berl) 153:155-169

Guyon A, Assouly-Besse F, Biala G, Puech AJ, Thiebot MH (1993) Potentiation by low doses of selected neuroleptics of foodinduced conditioned place preference in rats. Psychopharmacology (Berl) 110:460-466

Hall H, Sallemark M, Jerning E (1986) Effects of remoxipride and some related new substituted salicylamides on rat brain receptors. Acta Pharmacol Toxicol (Copenh) 58:61-70

Hietala J, Seppala T, Lappalainen J, Syvalahti E (1992) Quantification of SCH 39166, a novel selective D1 dopamine receptor antagonist, in rat brain and blood. Psychopharmacology (Berl) 106:455-458

Hillegaart V, Ahlenius S (1987) Effects of raclopride on exploratory locomotor activity, treadmill locomotion, conditioned avoidance behaviour and catalepsy in rats: behavioural profile comparisons between raclopride, haloperidol and preclamol. Pharmacol Toxicol 60:350-354

Hiroi N, White NM (1991) The amphetamine conditioned place preference: differential involvement of dopamine receptor subtypes and two dopaminergic terminal areas. Brain Res 552:141-152

Ho BT, Huang JT (1975) Role of dopamine in D-amphetamine-induced discriminative responding. Pharmacol Biochem Behav 3:10851092

Hoffman DC, Beninger RJ (1985) The D1 dopamine receptor antagonist, SCH 23390 reduces locomotor activity and rearing in rats. Pharmacol Biochem Behav 22:341-342

Hoffman DC, Donovan H (1995a) Effects of typical, atypical, and novel antipsychotic drugs on amphetamine-induced place conditioning in rats. Drug Dev Res 36:193-198 
Hoffman DC, Donovan H (1995b) Catalepsy as a rodent model for detecting antipsychotic drugs with extrapyramidal side effect liability. Psychopharmacology (Berl) 120:128-133

Hooks MS, Jones DN, Holtzman SG, Juncos JL, Kalivas PW, Justice JB Jr (1994) Individual differences in behavior following amphetamine, GBR-12909, or apomorphine but not SKF-38393 or quinpirole. Psychopharmacology (Berl) 116:217-225

Horvitz JC, Ettenberg A (1991) Conditioned incentive properties of a food-paired conditioned stimulus remain intact during dopamine receptor blockade. Behav Neurosci 105:536-541

Imperato A, Di Chiara G (1985) Dopamine release and metabolism in awake rats after systemic neuroleptics as studied by trans-striatal dialysis. J Neurosci 5:297-306

Ishiwata K, Kobayashi T, Kawamura K, Matsuno K, Senda M (2001) [11C]Raclopride binding was reduced in vivo by sigma(1) receptor ligand SA4503 in the mouse brain, while [11C]SA4503 binding was not by raclopride. Nucl Med Biol 28:787-792

Jafari S, Fernandez-Enright F, Huang XF (2012) Structural contributions of antipsychotic drugs to their therapeutic profiles and metabolic side effects. J Neurochem 120:371-384

Knutson B, Burgdorf J, Panksepp J (2002) Ultrasonic vocalizations as indices of affective states in rats. Psychol Bull 128:961-977

Le Foll B, Gallo A, Le SY, Lu L, Gorwood P (2009) Genetics of dopamine receptors and drug addiction: a comprehensive review. Behav Pharmacol 20:1-17

Leone P, Di Chiara G (1987) Blockade of D-1 receptors by SCH 23390 antagonizes morphine- and amphetamine-induced place preference conditioning. Eur J Pharmacol 135:251-254

Leyton M, aan het Rot M, Booij L, Baker GB, Young SN, Benkelfat C (2007) Mood-elevating effects of d-amphetamine and incentive salience: the effect of acute dopamine precursor depletion. J Psychiatry Neurosci 32:129-136

Leyton M, Casey KF, Delaney JS, Kolivakis T, Benkelfat C (2005) Cocaine craving, euphoria, and self-administration: a preliminary study of the effect of catecholamine precursor depletion. Behav Neurosci 119:1619-1627

Liao Y, Venhuis BJ, Rodenhuis N, Timmerman W, Wikstrom H, Meier E, Bartoszyk GD, Bottcher H, Seyfried CA, Sundell S (1999) New (sulfonyloxy)piperazinyldibenzazepines as potential atypical antipsychotics: chemistry and pharmacological evaluation. J Med Chem 42:2235-2244

Ljungberg T, Ungerstedt U (1985) A rapid and simple behavioural screening method for simultaneous assessment of limbic and striatal blocking effects of neuroleptic drugs. Pharmacol Biochem Behav 23:479-485

Maggio R, Aloisi G, Silvano E, Rossi M, Millan MJ (2009) Heterodimerization of dopamine receptors: new insights into functional and therapeutic significance. Parkinsonism Relat Disord 15(Suppl 4):S2-S7

McKittrick CR, Abercrombie ED (2007) Catecholamine mapping within nucleus accumbens: differences in basal and amphetamine-stimulated efflux of norepinephrine and dopamine in shell and core. J Neurochem 100:1247-1256

McMillen BA, German DC, Sanghere MK, Warnack W, Shore PA (1980) Pimozide: delayed onset of action at rat striatal pre- and postsynaptic dopamine receptors. J Pharmacol Exp Ther 215:150-155

McQuade RD, Duffy RA, Anderson CC, Crosby G, Coffin VL, Chipkin RE, Barnett A (1991a) [3H]SCH 39166, a new D1-selective radioligand: in vitro and in vivo binding analyses. J Neurochem 57:20012010

McQuade RD, Duffy RA, Coffin VL, Chipkin RE, Barnett A (1991b) In vivo binding of SCH 39166: a D-1 selective antagonist. J Pharmacol Exp Ther 257:42-49

Mehta MA, Sahakian BJ, McKenna PJ, Robbins TW (1999) Systemic sulpiride in young adult volunteers simulates the profile of cognitive deficits in Parkinson's disease. Psychopharmacology (Berl) 146:162-174

Menzaghi F, Whelan KT, Risbrough VB, Rao TS, Lloyd GK (1997) Effects of a novel cholinergic ion channel agonist SIB-1765F on locomotor activity in rats. J Pharmacol Exp Ther 280:384-392

Meyer ME, Cottrell GA, Van HC, Potter TJ (1993) Effects of dopamine D1 antagonists SCH23390 and SK\&F83566 on locomotor activities in rats. Pharmacol Biochem Behav 44:429-432

Millan MJ, Dekeyne A (2007) Discriminative stimulus properties of the selective norepinephrine reuptake inhibitor, reboxetine, in rats: a characterization with alpha/beta-adrenoceptor subtype selective ligands, antidepressants, and antagonists at neuropeptide receptors. Int J Neuropsychopharmacol 10:579-593

Millan MJ, Seguin L, Gobert A, Cussac D, Brocco M (2004) The role of dopamine D3 compared with D2 receptors in the control of locomotor activity: a combined behavioural and neurochemical analysis with novel, selective antagonists in rats. Psychopharmacology (Berl) 174:341-357

Mithani S, Martin-Iverson MT, Phillips AG, Fibiger HC (1986) The effects of haloperidol on amphetamine- and methylphenidateinduced conditioned place preferences and locomotor activity. Psychopharmacology (Berl) 90:247-252

Moore S, Kenyon P (1994) Atypical antipsychotics, clozapine and sulpiride do not antagonise amphetamine-induced stereotyped locomotion. Psychopharmacology (Berl) 114:123-130

Morelli M, Di CG (1985) Catalepsy induced by SCH 23390 in rats. Eur J Pharmacol 117:179-185

Morgenstern R, Fink H, Oelssner W (1983) LSD-potentiated apomorphine hypermotility: a model for differentiating antipsychotic drugs. Pharmacol Biochem Behav 18:13-17

Morpurgo C, Theobald W (1964) Influence of antiparkinson drugs and amphetamine on some pharmacological effects of phenothiazine derivatives used as neuroleptics. Psychopharmacologia 6:178-191

Nicklaus KJ, McGonigle P, Molinoff PB (1988) [3H]SCH 23390 labels both dopamine-1 and 5-hydroxytryptamine1c receptors in the choroid plexus. J Pharmacol Exp Ther 247:343-348

Nielsen EB, Andersen PH (1992) Dopamine receptor occupancy in vivo: behavioral correlates using NNC-112, NNC-687 and NNC756, new selective dopamine D1 receptor antagonists. Eur J Pharmacol 219:35-44

Nielsen EB, Jepsen SA (1985) Antagonism of the amphetamine cue by both classical and atypical antipsychotic drugs. Eur J Pharmacol 111:167-176

Nielsen EB, Randrup K, Andersen PH (1989) Amphetamine discrimination: effects of dopamine receptor agonists. Eur J Pharmacol 160:253-262

Ogren SO, Hall H, Kohler C, Magnusson O, Sjostrand SE (1986) The selective dopamine D2 receptor antagonist raclopride discriminates between dopamine-mediated motor functions. Psychopharmacology (Berl) 90:287-294

Ouagazzal A, Nieoullon A, Amalric M (1993) Effects of dopamine D1 and D2 receptor blockade on MK-801-induced hyperlocomotion in rats. Psychopharmacology (Berl) 111:427-434

Poncelet M, Dangoumau L, Soubrie P, Simon P (1987) Effects of neuroleptic drugs, clonidine and lithium on the expression of conditioned behavioral excitation in rats. Psychopharmacology (Berl) 92:393-397

Potvin S, Stip E, Roy JY (2003) Clozapine, quetiapine and olanzapine among addicted schizophrenic patients: towards testable hypotheses. Int Clin Psychopharmacol 18:121-132

Powell KR, Iuvone PM, Holtzman SG (2001) The role of dopamine in the locomotor stimulant effects and tolerance to these effects of caffeine. Pharmacol Biochem Behav 69:59-70

Prinssen EP, Ellenbroek BA, Stamatovic B, Cools AR (1993) The effects of haloperidol and raclopride in the paw test are influenced similarly by SCH 39166. Eur J Pharmacol 231:275-280 
Rama Rao VA, Bailey J, Bishop M, Coppen A (1981) A clinical and pharmacodynamic evaluation of sulpiride. Psychopharmacology (Berl) 73:77-80

Ramsson ES, Howard CD, Covey DP, Garris PA (2011) High doses of amphetamine augment, rather than disrupt, exocytotic dopamine release in the dorsal and ventral striatum of the anesthetized rat. J Neurochem 119:1162-1172

Rondou P, Haegeman G, Van CK (2010) The dopamine D4 receptor: biochemical and signalling properties. Cell Mol Life Sci 67:19711986

Sacaan AI, Menzaghi F, Dunlop JL, Correa LD, Whelan KT, Lloyd GK (1996) Epibatidine: a nicotinic acetylcholine receptor agonist releases monoaminergic neurotransmitters: in vitro and in vivo evidence in rats. J Pharmacol Exp Ther 276:509-515

Salmi P, Malmgren K, Svensson TH, Ahlenius S (1998) Stimulation of forward locomotion by SCH-23390 and raclopride in D-amphetamine-treated rats. Naunyn Schmiedebergs Arch Pharmacol 357:593-599

Sanchez C, Arnt J, Dragsted N, Hyttel J, Lembol HL, Meier E, Perregaard J, Skarsfeldt T (1991) Neurochemical and in vivo pharmacological profile of sertindole, a limbic-selective neuroleptic compound. Drug Dev Res 22:239-250

Schaefer GJ, Michael RP (1984) Drug interactions on spontaneous locomotor activity in rats. Neuroleptics and amphetamineinduced hyperactivity. Neuropharmacology 23:909-914

Schroeder JP, Packard MG (2000) Role of dopamine receptor subtypes in the acquisition of a testosterone conditioned place preference in rats. Neurosci Lett 282:17-20

Seeman P, Van Tol HH (1994) Dopamine receptor pharmacology. Trends Pharmacol Sci 15:264-270

Seeman P, Corbett R, Van Tol HH (1997) Atypical neuroleptics have low affinity for dopamine D2 receptors or are selective for D4 receptors. Neuropsychopharmacology 16:93-110

Sharp T, Zetterstrom T, Ljungberg T, Ungerstedt U (1986) Effect of sulpiride on amphetamine-induced behaviour in relation to changes in striatal dopamine release in vivo. Eur $\mathrm{J}$ Pharmacol 129:411-415

Shen YL, Chen YC, Liao RM (2010) Dopamine receptor antagonists impair place conditioning after acute stress in rats. Behav Pharmacol 21:77-82

Shippenberg TS, Herz A (1987) Place preference conditioning reveals the involvement of D1-dopamine receptors in the motivational properties of mu- and kappa-opioid agonists. Brain Res 436:169172

Shippenberg TS, Herz A (1988) Motivational effects of opioids: influence of D-1 versus D-2 receptor antagonists. Eur J Pharmacol 151:233-242

Simola N, Ma ST, Schallert T (2009) Influence of acute caffeine on 50$\mathrm{kHz}$ ultrasonic vocalizations in male adult rats and relevance to caffeine-mediated psychopharmacological effects. Int J Neuropsychopharmacol 13:123-132

Smith FL, St JC, Yang TF, Lyness WH (1989) Role of specific dopamine receptor subtypes in amphetamine discrimination. Psychopharmacology (Berl) 97:501-506

Smith KS, Berridge KC, Aldridge JW (2011) Disentangling pleasure from incentive salience and learning signals in brain reward circuitry. Proc Natl Acad Sci U S A 108:E255-E264

Sorge RE, Clarke PB (2009) Rats self-administer intravenous nicotine delivered in a novel smoking-relevant procedure: effects of dopamine antagonists. J Pharmacol Exp Ther 330:633-640

Spivak KJ, Amit Z (1986) Effects of pimozide on appetitive behavior and locomotor activity: dissimilarity of effects when compared to extinction. Physiol Behav 36:457-463

Spyraki C, Fibiger HC, Phillips AG (1982) Dopaminergic substrates of amphetamine-induced place preference conditioning. Brain Res 253:185-193
Tagliamonte A, DeMontis G, Olianas M, Vargiu L, Corsini GU, Gessa GL (1975) Selective increase of brain dopamine synthesis by sulpiride. J Neurochem 24:707-710

Taracha E, Hamed A, Krzascik P, Lehner M, Skorzewska A, Plaznik A, Chrapusta SJ (2012) Inter-individual diversity and intra-individual stability of amphetamine-induced sensitization of frequency-modulated $50-\mathrm{kHz}$ vocalization in Sprague-Dawley rats. Psychopharmacology (Berl) 222:619632

Thompson B, Leonard KC, Brudzynski SM (2006) Amphetamineinduced $50 \mathrm{kHz}$ calls from rat nucleus accumbens: a quantitative mapping study and acoustic analysis. Behav Brain Res 168:64 73

Tice MA, Hashemi T, Taylor LA, Duffy RA, McQuade RD (1994) Characterization of the binding of SCH 39166 to the five cloned dopamine receptor subtypes. Pharmacol Biochem Behav 49:567571

Tzschentke TM (1998) Measuring reward with the conditioned place preference paradigm: a comprehensive review of drug effects, recent progress and new issues. Prog Neurobiol 56:613672

Varty GB, Higgins GA (1997) Investigations into the nature of a 7-OHDPAT discriminative cue: comparison with D-amphetamine. Eur J Pharmacol 339:101-107

Vivian JA, Miczek KA (1991) Ultrasounds during morphine withdrawal in rats. Psychopharmacology (Berl) 104:187-193

Voruganti L, Awad AG (2004) Neuroleptic dysphoria: towards a new synthesis. Psychopharmacology (Berl) 171:121-132

Voruganti L, Cortese L, Oyewumi L, Cernovsky Z, Zirul S, Awad A (2000) Comparative evaluation of conventional and novel antipsychotic drugs with reference to their subjective tolerability, side-effect profile and impact on quality of life. Schizophr Res 43:135-145

Wadenberg ML, Hertel P, Fernholm R, Hygge BK, Ahlenius S, Svensson TH (2000a) Enhancement of antipsychotic-like effects by combined treatment with the alpha1-adrenoceptor antagonist prazosin and the dopamine D2 receptor antagonist raclopride in rats. J Neural Transm 107:1229-1238

Wadenberg ML, Kapur S, Soliman A, Jones C, Vaccarino F (2000b) Dopamine D2 receptor occupancy predicts catalepsy and the suppression of conditioned avoidance response behavior in rats. Psychopharmacology (Berl) 150:422-429

Wall SC, Gu H, Rudnick G (1995) Biogenic amine flux mediated by cloned transporters stably expressed in cultured cell lines: amphetamine specificity for inhibition and efflux. Mol Pharmacol 47:544-550

Wamsley JK, Hunt ME, McQuade RD, Alburges ME (1991) [3H] SCH39166, a D1 dopamine receptor antagonist: binding characteristics and localization. Exp Neurol 111:145-151

West WB, Van Groll BJ, Appel JB (1995) Stimulus effects of damphetamine II: DA, NE, and 5-HT mechanisms. Pharmacol Biochem Behav 51:69-76

White IM, Ciancone MT, Haracz JL, Rebec GV (1992) A lever-release version of the conditioned avoidance response paradigm: effects of haloperidol, clozapine, sulpiride, and BMY-14802. Pharmacol Biochem Behav 41:29-35

Williams SN, Undieh AS (2010) Brain-derived neurotrophic factor signaling modulates cocaine induction of reward-associated ultrasonic vocalization in rats. J Pharmacol Exp Ther 332:463468

Wintink AJ, Brudzynski SM (2001) The related roles of dopamine and glutamate in the initiation of $50-\mathrm{kHz}$ ultrasonic calls in adult rats. Pharmacol Biochem Behav 70:317-323

Wohr M, Schwarting RK (2010) Rodent ultrasonic communication and its relevance for models of neuropsychiatric disorders. eNeuroforum 1:71-80 
Wohr M, Houx B, Schwarting RK, Spruijt B (2008) Effects of experience and context on $50-\mathrm{kHz}$ vocalizations in rats. Physiol Behav 93:766-776

Wong DT, Bymaster FP (1976) Effect of nisoxetine on uptake of catecholamines in synaptosomes isolated from discrete regions of rat brain. Biochem Pharmacol 25:1979-1983

Wong DT, Threlkeld PG, Best KL, Bymaster FP (1982) A new inhibitor of norepinephrine uptake devoid of affinity for receptors in rat brain. J Pharmacol Exp Ther 222:61-65

Wright JM, Gourdon JC, Clarke PB (2010) Identification of multiple call categories within the rich repertoire of adult rat $50-\mathrm{kHz}$ ultrasonic vocalizations: effects of amphetamine and social context. Psychopharmacology (Berl) 211:1-13

Wright JM, Deng L, Clarke PB (2012a) Failure of rewarding and locomotor stimulant doses of morphine to promote adult rat 50$\mathrm{kHz}$ ultrasonic vocalizations. Psychopharmacology (Berl) (in press)

Wright JM, Dobosiewicz MR, Clarke PB (2012b) Alpha- and beta-adrenergic receptors differentially modulate the emission of spontaneous and amphetamine-induced $50-\mathrm{kHz}$ ultrasonic vocalizations in adult rats. Neuropsychopharmacology 37:808821 